University of Wollongong

Research Online

Australian Institute for Innovative Materials -

Papers

Australian Institute for Innovative Materials

$1-1-2012$

Structure determination of an amorphous compound AIB4H11

Xuenian Chen

Ohio State University

Yongsheng Zhang

Northwestern University

Yongli Wang

Northwestern University

Wei Zhou

University of Maryland, Nist Center For Neutron Research, National Institute Of Standards And Technology

Douglas A. Knight

Savannah River National Laboratory

See next page for additional authors

Follow this and additional works at: https://ro.uow.edu.au/aiimpapers

Part of the Engineering Commons, and the Physical Sciences and Mathematics Commons

Research Online is the open access institutional repository for the University of Wollongong. For further information contact the UOW Library: research-pubs@uow.edu.au 


\section{Structure determination of an amorphous compound AlB4H11}

\section{Keywords}

alb4h11, compound, amorphous, determination, structure

\section{Disciplines}

Engineering | Physical Sciences and Mathematics

\section{Publication Details}

Chen, X., Zhang, Y., Wang, Y., Wang, Y., Zhou, W., Knight, D. A., Yisgedu, T., Huang, Z., Lingam, H., Billet, B., Udovic, T. J., G Brown, G., Shore, S. G., Wolverton, C. \& Zhao, J. (2012). Structure determination of an amorphous compound AlB4H11. Chemical Science,

\section{Authors}

Xuenian Chen, Yongsheng Zhang, Yongli Wang, Wei Zhou, Douglas A. Knight, Teshome B. Yisgedu, Zhenguo Huang, Hima Kumar Lingam, Beau Billet, Terrence J. Udovic, Gilbert M. Brown, Sheldon G. Shore, Christopher Wolverton, and Ji-Cheng Zhao 


\section{Structure determination of an amorphous compound $\mathrm{AlB}_{4} \mathrm{H}_{11} \dagger$}

\author{
Xuenian Chen, ${ }^{a b}$ Yongsheng Zhang, ${ }^{c}$ Yongli Wang, ${ }^{c}$ Wei Zhou, ${ }^{d e}$ Douglas A. Knight, ${ }^{f}$ Teshome B. Yisgedu, ${ }^{a}$ \\ Zhenguo Huang, ${ }^{a}$ Hima K. Lingam, ${ }^{a}$ Beau Billet, ${ }^{a}$ Terrence J. Udovic, ${ }^{* d}$ Gilbert M. Brown, ${ }^{* g}$ \\ Sheldon G. Shore, ${ }^{* b}$ Christopher Wolverton ${ }^{* c}$ and Ji-Cheng Zhao ${ }^{* a}$
}

\author{
Received 28th July 2012, Accepted 20th August 2012 \\ DOI: 10.1039/c2sc21100a
}

\begin{abstract}
The structure of the amorphous aluminoborane compound $\mathrm{AlB}_{4} \mathrm{H}_{11}$ was identified through a collaborative study closely coupling a first-principles density functional based approach with experimental measurements using IR, NMR, and neutron vibrational spectroscopy (NVS). The $\mathrm{AlB}_{4} \mathrm{H}_{11}$ structure was found to contain distinct $\left[\mathrm{BH}_{4}\right]$ and $\left[\mathrm{B}_{3} \mathrm{H}_{7}\right]$ units without any $\left[\mathrm{AlH}_{4}\right]$ units. It forms a $-\left[\mathrm{B}_{3} \mathrm{H}_{7}\right]-\mathrm{Al}\left(\mathrm{BH}_{4}\right)$ - polymer chain with the $\left[\mathrm{BH}_{4}\right]$ units twisted relative to each other perpendicular to the chain direction and bonded to $\mathrm{Al}$, and a chain backbone consists of $\left[\mathrm{B}_{3} \mathrm{H}_{7}\right]$ and $\mathrm{Al}$ where the $\left[\mathrm{B}_{3} \mathrm{H}_{7}\right]$ unit exhibits a triangular boron configuration. The computed lowest energy structure shows good agreement with results of IR, NVS and NMR spectra; this agreement demonstrates the extended applicability of the structure prediction approach to the prediction of even amorphous compounds.
\end{abstract}

\section{Introduction}

The aluminoborane compound $\mathrm{AlB}_{4} \mathrm{H}_{11}$ was first prepared in 1981 by Himpsl and Bond from a reaction between $\mathrm{Al}\left(\mathrm{BH}_{4}\right)_{3}$ and $\mathrm{B}_{2} \mathrm{H}_{6}$ at $100{ }^{\circ} \mathrm{C}^{1}{ }^{1}$ This synthesis was reproduced about a quarter of a century later by Zhao et al. in search of high-capacity hydrogen storage materials. ${ }^{2} \mathrm{AlB}_{4} \mathrm{H}_{11}$ is an amorphous white solid at ambient temperature with several properties that are attractive for hydrogen storage: (1) a high hydrogen content of 13.5 mass \%, (2) moderate stability with a decomposition temperature around $125{ }^{\circ} \mathrm{C}$, (3) release of predominantly hydrogen in the desorbed gas, (4) endothermic desorption which is thermodynamically essential for rehydrogenation, and (5) partial rehydrogenation at moderate conditions (which is

${ }^{a}$ Department of Materials Science and Engineering, The Ohio State University, Columbus, OH 43210,USA.E-mail: zhao.199@osu.edu

${ }^{b}$ Department of Chemistry, The Ohio State University, Columbus, $\mathrm{OH}$ 43210,USA. E-mail: shore.1@osu.edu

'Department of Materials Science and Engineering, Northwestern University, Evanston, IL 60208, USA. E-mail: c-wolverton@, northwestern.edu

${ }^{d}$ NIST Center for Neutron Research, National Institute of Standards and Technology, Gaithersburg, MD 20899,USA. E-mail: terrence.udovic@, nist.gov

${ }^{e}$ Department of Materials Science and Engineering, University of Maryland, College Park, MD 20742, USA

${ }^{f}$ Savannah River National Laboratory, Aiken, SC 29808, USA

${ }^{g}$ Oak Ridge National Laboratory, Oak Ridge, TN 37831, USA. E-mail. browngm1@ornl.gov

$\uparrow$ Electronic supplementary information (ESI) available: For details of the crystal structure information for structures Str-0, Str-86, Str-108, Str-260, Str-400, and Str-640, ${ }^{11}$ B NMR spectra information. See DOI: $10.1039 / \mathrm{c} 2 \mathrm{sc} 21100 \mathrm{a}$ relatively rare for borane compounds). ${ }^{2}$ These properties of $\mathrm{AlB}_{4} \mathrm{H}_{11}$, in contrast to those of other borane compounds, seem to suggest a completely unique structure. ${ }^{2}$ A structure proposed by Himpsl and Bond based on the analogue to pentaborane $\left(\mathrm{B}_{5} \mathrm{H}_{11}\right)$ is inconsistent with the IR and ${ }^{11} \mathrm{~B}$ NMR spectra of $\mathrm{AlB}_{4} \mathrm{H}_{11} \cdot{ }^{1,2}$ Hence, the determination of the $\mathrm{AlB}_{4} \mathrm{H}_{11}$ structure is significant for the understanding of its stability and hydrogenation/dehydrogenation properties.

The amorphous nature of $\mathrm{AlB}_{4} \mathrm{H}_{11}$ and its insolubility in organic solvents prevent us from determining its structure using XRD, neutron diffraction, solution NMR, or mass spectrometry techniques. Solid-state NMR and vibrational spectra were found to be insufficient for even speculating on its structure. Instead, a novel combination of experimental measurements (NMR, IR, and neutron vibrational spectroscopy (NVS)) with a theoretical prediction method (the Monte-Carlo based prototype electrostatic ground state search (PEGS) with density functional theory (DFT) calculations) are used to identify local structures of this amorphous $\mathrm{AlB}_{4} \mathrm{H}_{11}$ phase as schematically depicted in Fig. 1.

We measured the vibrational spectra of $\mathrm{AlB}_{4} \mathrm{H}_{11}$ and in parallel used the PEGS + DFT method to predict the preliminary $\mathrm{AlB}_{4} \mathrm{H}_{11}$ structures and computed their phonon density of states (pDOS) from DFT. For each theoretical structure, we compared the calculated pDOS with the measured vibration spectra to determine the atomic arrangements represented in the amorphous structure. Based on these theoretical predictions, additional experiments were performed to confirm these atomic arrangements. The PEGS + DFT method was employed again to refine the low-energy structures, using experimentally and theoretically confirmed anion groups as input. This closely coupled, iterative experimental/theoretical procedure terminates when 


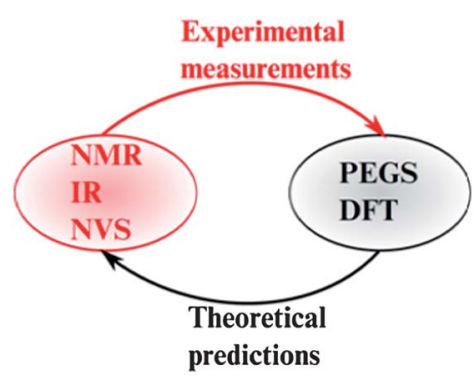

Fig. 1 Schematic of an iterative procedure integrating experimental measurements with theoretical predictions to identify the structure of $\mathrm{AlB}_{4} \mathrm{H}_{11}$.

there is good agreement between experimental measurements and theoretical predictions (Fig. 1).

The structure prediction methodology utilized here, PEGS + DFT, has previously successfully predicted crystal structures of complex hydrides with anion groups like $\left[\mathrm{BH}_{4}\right]^{-},\left[\mathrm{B}_{2} \mathrm{H}_{n}\right]^{2-}$, $\left[\mathrm{B}_{3} \mathrm{H}_{n}\right]^{x-}$, and $\left[\mathrm{B}_{12} \mathrm{H}_{12}\right]^{2-} \cdot{ }^{3-6}$ However, the structural determination of $\mathrm{AlB}_{4} \mathrm{H}_{11}$ is significantly more challenging than these previous cases in two crucial aspects: (1) in these previously predicted structures, the cation and anion groups were known. For $\mathrm{AlB}_{4} \mathrm{H}_{11}$, we know only its stoichiometry and nothing of local geometries or the cationic and anionic units. (2) In all previous structural predictions, the compounds were perfectly crystalline. In order to overcome these barriers and predict lowenergy $\mathrm{AlB}_{4} \mathrm{H}_{11}$ structures using PEGS + DFT, we first hypothetically split the $\mathrm{AlB}_{4} \mathrm{H}_{11}$ stoichiometry into small fragments to make a fragment pool: $\mathrm{Al},\left[\mathrm{AlH}_{4}\right],\left[\mathrm{BH}_{4}\right],\left[\mathrm{BH}_{3}\right],\left[\mathrm{BH}_{2}\right]$, and $[\mathrm{BH}]$. In this pool, we chose different combinations (like Groups 1 and 2 in Fig. 2) as inputs to PEGS to build $\mathrm{AlB}_{4} \mathrm{H}_{11}$ and predicted its preliminary low-energy structures. By comparing the theoretically predicted local geometry with the structural information from experimental observations, we then refined our inputs for further PEGS predictions. Additional experimental measurements were performed to further define the structure. Our closely coupled theoretical and experimental approach gives an example of how to solve difficult structures such as $\mathrm{AlB}_{4} \mathrm{H}_{11}$. Our work also extends the application of the PEGS + DFT predictions to

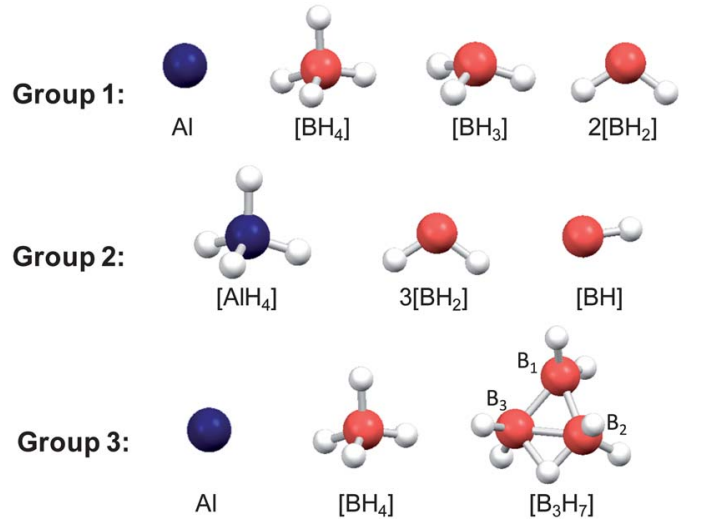

Fig. 2 The $\mathrm{AlB}_{4} \mathrm{H}_{11}$ stoichiometry was split into $\mathrm{Al}+\left[\mathrm{BH}_{4}\right]+\left[\mathrm{BH}_{3}\right]+2$ $[\mathrm{BH}]\left(\right.$ Group 1), $\left[\mathrm{AlH}_{4}\right]+3\left[\mathrm{BH}_{2}\right]+[\mathrm{BH}]\left(\right.$ Group 2), and $\mathrm{Al}+\left[\mathrm{BH}_{4}\right]+$ $\left[\mathrm{B}_{3} \mathrm{H}_{7}\right]$ (Group 3), respectively. $\mathrm{Al}=$ blue, $\mathrm{B}=$ orange, $\mathrm{H}=$ white gray. amorphous structures when certain structural fragments can be guessed or deduced from experimental information or chemical intuition.

\section{Experimental and computational methodology}

\subsection{General comments}

All manipulations were carried out on a standard high vacuum line, in a drybox or air bag under an atmosphere of nitrogen or argon. Ammonia (Matheson), ${ }^{7}$ sodium borohydride (GFS, Chemicals), iodine (GFS Chemicals), and anhydrous aluminum chloride (Aldrich) were used as received. Benzene and 1,2dimethoxyethane were dried over sodium-benzophenone and freshly distilled prior to use. NVS of $\mathrm{AlB}_{4} \mathrm{H}_{11}$ was performed at $4 \mathrm{~K}$ with the Filter Analyzer Neutron Spectrometer ${ }^{8}$ at NIST with $60^{\prime}$ and $40^{\prime}$ horizontal collimations before and after the $\mathrm{Cu}(220)$ monochromator, respectively. ${ }^{11} \mathrm{~B}$ and ${ }^{11} \mathrm{~B}\left\{{ }^{1} \mathrm{H}\right\}$ NMR spectra were recorded on a Bruker AM-400 spectrometer at 128.4 $\mathrm{MHz}$, and externally referenced to $\mathrm{BF}_{3} \cdot \mathrm{OEt}_{2}$ in $\mathrm{C}_{6} \mathrm{D}_{6}(\delta=0.00$ ppm). ${ }^{27} \mathrm{Al}$ NMR spectra were obtained at $104.3 \mathrm{MHz}$ for ${ }^{27} \mathrm{Al}$ nuclei using $\left[\mathrm{Al}\left(\mathrm{H}_{2} \mathrm{O}\right)_{6}\right]^{3+}$ as reference $(\delta=0.00 \mathrm{ppm})$. Infrared spectra were recorded on a Mattson-Polaris FT-IR spectrometer with $2 \mathrm{~cm}^{-1}$ resolution.

\subsection{Reaction of $\mathrm{Al}\left(\mathrm{BH}_{4}\right)_{3}$ with $\mathrm{B}_{2} \mathrm{H}_{6}$ monitored by ${ }^{11} \mathrm{~B}$ and ${ }^{11} \mathrm{~B}$ $\left\{{ }^{1} \mathbf{H}\right\}$ NMR}

In order to investigate the formation mechanism of $\mathrm{AlB}_{4} \mathrm{H}_{11}$, the reaction between $\mathrm{Al}\left(\mathrm{BH}_{4}\right)_{3}$ and $\mathrm{B}_{2} \mathrm{H}_{6}$ was monitored using ${ }^{11} \mathrm{~B}$ and ${ }^{11} \mathrm{~B}\left\{{ }^{1} \mathrm{H}\right\}$ NMR. Because the reaction must be performed at $100{ }^{\circ} \mathrm{C}$ under a positive diborane pressure (about $1.5 \mathrm{~atm}$ ), ${ }^{1} \mathrm{a}$ special apparatus was designed and connected to the top of a reactor to avoid diborane from escaping when samples were withdrawn (Fig. S1, $\uparrow$ note stoppers 1 and 2 on the apparatus). In the reactor, $7.5 \mathrm{mmol} \mathrm{Al}\left(\mathrm{BH}_{4}\right)_{3}$ and $15.0 \mathrm{mmol} \mathrm{B}_{2} \mathrm{H}_{6}$, both freshly prepared using literature methods, ${ }^{9,10}$ were introduced. A sample of the reaction solution was withdrawn at three hour intervals for analysis. To withdraw a sample, the reactor was removed from an oil bath to an air bag. Stopper 2 was turned to an open position and the reactor was turned upside down to allow the reaction solution to fully fill the small space between stoppers 1 and 2. Then stopper 2 was closed and stopper 1 was turned open, and the sample was pipetted into an NMR tube. After the sample collection, stopper 1 was closed and the reactor was restored to initial reaction conditions. All collected samples were examined using ${ }^{11} \mathrm{~B}$ and ${ }^{11} \mathrm{~B}\left\{{ }^{1} \mathrm{H}\right\}$ NMR.

\subsection{Density-functional theory calculations}

DFT calculations were performed using the Vienna Ab Initio Simulation Package (VASP) code with the projector augmented wave (PAW) scheme, ${ }^{11}$ and the generalized gradient approximation of Perdew and Wang ${ }^{12}$ (GGA-PW91) for the electronic exchange-correlation functional. We used an energy cutoff for the plane wave expansion of $875 \mathrm{eV}$. We sampled Brillouin zones using Monkhorst-Pack ${ }^{13} k$-point meshes for all compounds with meshes chosen to give a roughly constant density of $k$-points (30 $\AA^{-3}$ ) for all compounds. Tests show that our $k$-point meshes yield energies that are converged to within $0.01 \mathrm{eV}$ per formula 
unit (fu). Atomic positions and the unit cell were both relaxed until all the forces and components of the stress tensor were below $0.01 \mathrm{eV} \AA^{-1}$ and $0.2 \mathrm{kbar}$, respectively. Phonons were calculated using the supercell force constant method as implemented in the program described by Wolverton et al. ${ }^{14}$ and the vibrational entropies and enthalpies were obtained by directly summing over the calculated phonon frequencies.

\subsection{Structure prediction method}

While DFT calculations are typically quite accurate for hydride systems, ${ }^{14}$ a direct prediction of unknown crystal structures from DFT is difficult due to the large configuration space which must be explored. For our crystal structure prediction task, we turned to the prototype electrostatic ground state (PEGS) search method $^{15}$ in which the hydride system is described by a combination of electrostatic potential and soft sphere repulsion:

$$
E_{\mathrm{tot}}^{\mathrm{PEGS}}= \begin{cases}\sum_{i>j} \frac{Q_{i} Q_{j}}{d_{i j}}+\sum_{i>j} \frac{1}{d_{i j}{ }^{12}} & d_{i j}<\left(R_{i}+R_{j}\right) \\ \sum_{i>j} \frac{Q_{i} Q_{j}}{d_{i j}} & d_{i j} \geq\left(R_{i}+R_{j}\right)\end{cases}
$$

where each atom $i$ is represented by a radius $\left(R_{i}\right)$ and a charge $\left(Q_{j}\right)$, and $d_{i j}$ is the separation distance between atoms $i$ and $j$. The first term is the point charge electrostatic energy, while the second term is a repulsive soft-sphere potential. The Coulomb interactions are calculated for all pairs of atoms, regardless of distance, while the soft-sphere interactions are only non-zero when atomic spheres $(R)$ overlap. The PEGS method requires the division of the solid into cationic and anionic units (which are treated as rigid units during Monte Carlo simulations, described below). In order to obtain preliminary structures of the amorphous $\mathrm{AlB}_{4} \mathrm{H}_{11}$ phase, we arbitrarily chose two groups of cation and anion units to form $\mathrm{AlB}_{4} \mathrm{H}_{11}: \mathrm{Al}+\left[\mathrm{BH}_{4}\right]+\left[\mathrm{BH}_{3}\right]+2\left[\mathrm{BH}_{2}\right]$ (Group 1 in Fig. 2) and $\left[\mathrm{AlH}_{4}\right]+3\left[\mathrm{BH}_{2}\right]+[\mathrm{BH}]$ (Group 2 in Fig. 2). We obtained the cation ionic radii of $\mathrm{Al}$ from standard sources $(R=0.5 \AA),{ }^{16}$ and its ionic charge was given a nominal value of $+3 \mathrm{e}$. The ionic radii and ionic charges of $\mathrm{B}, \mathrm{Al}$ and $\mathrm{H}$ for anion groups $\left[\mathrm{BH}_{4}\right]^{-}$and $\left[\mathrm{AlH}_{4}\right]^{-}$as well as the ionic radii of $\mathrm{B}$ and $\mathrm{H}$ for the $\left[\mathrm{BH}_{3}\right],\left[\mathrm{BH}_{2}\right]$, and $[\mathrm{BH}]$ units were all taken from the literature. ${ }^{3,15}$ The anionic group charges for $\left[\mathrm{BH}_{3}\right],\left[\mathrm{BH}_{2}\right]$, $[\mathrm{BH}]$ were unknown, and we used our chemical intuition to assign charges to $\mathrm{B}$ and $\mathrm{H}$ in the anion units such that the charges of $\left[\mathrm{BH}_{3}\right]^{0}$ and $\left[\mathrm{BH}_{2}\right]^{-}$in Group 1 and $\left[\mathrm{BH}_{2}\right]^{+}$and $[\mathrm{BH}]^{2-}$ in Group 2 could balance the well-known charged units $\left(\left[\mathrm{BH}_{4}\right]^{-}\right.$ and $\mathrm{Al}^{3+}$ in Group 1, and $\left[\mathrm{AlH}_{4}\right]^{-}$in Group 2). For Group 3 (Fig. 2), the ionic radii of $\mathrm{B}$ and $\mathrm{H}$ in $\left[\mathrm{B}_{3} \mathrm{H}_{7}\right]$ were taken from the $\left[\mathrm{B}_{2} \mathrm{H}_{6}\right]^{2-}$ unit in our previously published paper. ${ }^{4}$ The charges distributed on atoms in the $\left[\mathrm{B}_{3} \mathrm{H}_{7}\right]^{2-}$ group $\left(\left[\mathrm{B}_{3} \mathrm{H}_{7}\right]\right.$ was set to -2 to balance the charges of $\mathrm{Al}^{3+}$ and $\left[\mathrm{BH}_{4}\right]^{-}$) were computed by the GAMESS cluster code. ${ }^{17}$ All anion group parameters are given in Table 1.

After setting up the PEGS input parameters, this computationally inexpensive electrostatic and repulsive potential was used in Monte Carlo (MC) simulations. We applied 30 PEGS annealing simulations with different initial random seeds (Fig. 2) of varying formula units (fu) for each group. During PEGS simulations, we kept each anion group as a rigid unit but allowed
Table 1 Cation and anion radii $(R)$ and charges $(Q)$ in PEGS simulations. In the $\left[\mathrm{B}_{3} \mathrm{H}_{7}\right]^{2-}$ unit, the $\mathrm{B}$ charges are in the sequence of $\mathrm{B}_{1} / \mathrm{B}_{2} / \mathrm{B}_{3}$ in Fig. 2, and the $\mathrm{H}$ charges are in the sequence of bonding with $\mathrm{B}_{1} / \mathrm{B}_{2} / \mathrm{B}_{3}$, and a bridging $\mathrm{H}$

\begin{tabular}{llllllll}
\hline & {$\left[\mathrm{BH}_{4}\right]^{-}$} & {$\left[\mathrm{BH}_{3}\right]^{0}$} & {$\left[\mathrm{BH}_{2}\right]^{-}$} & {$\left[\mathrm{BH}_{2}\right]^{+}$} & {$[\mathrm{BH}]^{2-}$} & {$\left[\mathrm{B}_{3} \mathrm{H}_{7}\right]^{2-}$} & {$\left[\mathrm{AlH}_{4}\right]^{-}$} \\
\hline$R_{\mathrm{B} / \mathrm{Al}}$ & 0.93 & 0.93 & 0.93 & 0.93 & 0.93 & 1.8 & 0.5 \\
$R_{\mathrm{H}}$ & 1.3 & 1.3 & 1.3 & 1.3 & 1.3 & 1.52 & 1.5 \\
$Q_{\mathrm{B} / \mathrm{Al}}$ & -0.7 & -3 & -3 & -1 & -3 & $0.08 /-0.19 /$ & 1.67 \\
$Q_{\mathrm{H}}$ & -0.075 & 1 & 1 & 1 & 1 & $\begin{array}{l}-0.19 \\
-0.33 /-0.247 /\end{array}$ & -0.6675 \\
& & & & & & & \\
\end{tabular}

it to rotate and translate. In the MC simulations, the MC movements included cation atom displacements, anion group displacements, anion group rotations, cation/anion swaps, and unit cell vector distortions and volume changes.

Although PEGS MC simulations provide many candidate structures, the calculated electrostatic potential is too crude to be used alone to predict quantitatively accurate crystal structures. Hence, accurate methods like DFT calculations are needed to carry out a full relaxation of the PEGS output structures. We performed DFT calculations on all structures that resulted from our PEGS outputs, and selected the compounds with the low DFT energies as candidates for the stable structure. We note that during the course of the DFT relaxation, energetically unfavorable anion groups can rearrange into more favorable groups, thus giving us information about preferred anionic units.

\subsection{Simulation of vibration spectra based upon the predicted structure of $\mathrm{AlB}_{4} \mathrm{H}_{11}$}

For comparison with NVS measurements, the phonon densities of states (pDOS) were calculated from the DFT-optimized structures using the supercell method $(2 \times 2 \times 1$ cell size $)$ with finite displacements ${ }^{18}$ and were appropriately weighted to take into account the $\mathrm{H}, \mathrm{B}$, and $\mathrm{Al}$ total neutron scattering cross sections.

\subsection{Simulation of ${ }^{11} B$ NMR spectra based upon the predicted structure of $\mathrm{AlB}_{4} \mathrm{H}_{11}$}

The ${ }^{11} \mathrm{~B}$ NMR shifts were calculated using the GIPAW method as implemented in the Quantum ESPRESSO package. ${ }^{19}$ The ${ }^{11} \mathrm{~B}$ NMR GIPAW chemical shifts were referenced to $\mathrm{B}_{2} \mathrm{H}_{6}$ (by ensuring that the theoretical ${ }^{11} \mathrm{~B}$ chemical shift of $\mathrm{B}_{2} \mathrm{H}_{6}$ coincided with its experimental value, $\delta 16.6 \mathrm{ppm}$ referenced to $\mathrm{BF}_{3} \cdot \mathrm{OEt}_{2}$ in $\left.\mathrm{C}_{6} \mathrm{D}_{6}(\delta=0.00 \mathrm{ppm})\right)$.

\section{Results and discussion}

\subsection{Prediction of preliminary $\mathrm{AlB}_{4} \mathrm{H}_{11}$ structures using two arbitrary groups}

From PEGS + DFT predictions, Str-400 and Str-640 (Fig. 3) are the lowest-energy, one-formula-unit (fu) $\mathrm{AlB}_{4} \mathrm{H}_{11}$ crystal structures derived from Groups 1 and 2 (Fig. 2), respectively. (The number in the nomenclature is the energy difference in $\mathrm{meV}$ relative to the theoretically predicted lowest-energy $\mathrm{AlB}_{4} \mathrm{H}_{11}$ structure, e.g., Str-400 is $400 \mathrm{meV}$ per formula unit higher in 

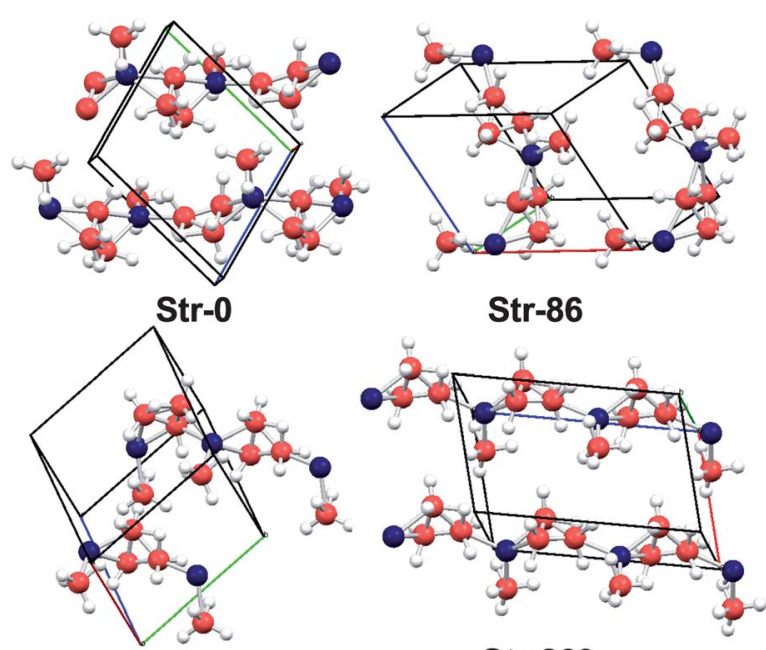

Str-108

Str-260
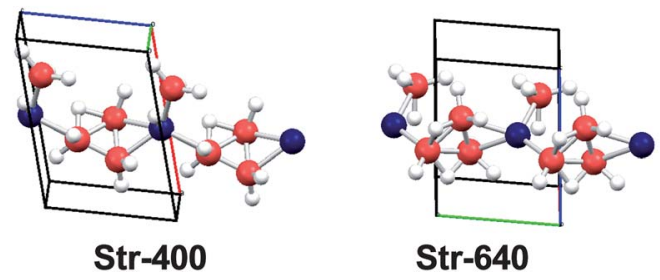

Fig. 3 PEGS + DFT theoretically predicted $\mathrm{AlB}_{4} \mathrm{H}_{11}$ crystal structures using the fragment groups in Fig. 2. The number in the nomenclature is the energy difference relative to the theoretically predicted lowest-energy $\mathrm{AlB}_{4} \mathrm{H}_{11}$ structure. Str- 640 and Str- 400 were obtained using Group 1 and Group 2 inputs in Fig. 2, respectively, and Str-0, Str-86, Str-108 and Str260 are obtained using Group 3 inputs in Fig. 2. All bonds between bridge hydrogen and aluminum were omitted for clarity. $\mathrm{Al}=$ blue, $\mathrm{B}=$ orange, $\mathrm{H}=$ white gray. (The crystal structure information for these compounds is given in Table $\mathrm{S} 1$ in the ESI $\dagger$ ).

energy than the lowest-energy predicted structure.) It can be seen that the small fragments in Fig. $2\left([\mathrm{BH}],\left[\mathrm{BH}_{2}\right]\right.$ and $\left.\left[\mathrm{BH}_{3}\right]\right)$ initially input into PEGS combined themselves to form a larger $\mathrm{B}_{3}$ unit (Fig. 3) after DFT relaxation/optimization. The $\left[\mathrm{AlH}_{4}\right]^{-}$ unit was an input to PEGS predictions in Group 2; it was found to be unstable during the DFT relaxation in all PEGS structures, and the $\mathrm{Al}-\mathrm{H}$ bonds were broken and the related hydrogen atoms were attracted by B units: in the lower-energy Str-400, $\left[\mathrm{BH}_{4}\right]^{-}$and $\left[\mathrm{B}_{3} \mathrm{H}_{7}\right]^{2-}$ units were formed (Str-400 in Fig. 3). This $\left[\mathrm{AlH}_{4}\right]^{-}$dissociation suggests that the $\mathrm{AlB}_{4} \mathrm{H}_{11}$ compound does not prefer to contain the $\left[\mathrm{AlH}_{4}\right]^{-}$unit. Both Str-640 and Str-400 form a $-\left[\mathrm{B}_{3} \mathrm{H}_{7}\right]-\mathrm{Al}\left(\mathrm{BH}_{4}\right)-$ chain (Fig. 3). This kind of polymer chain structure is likely to be the base of an amorphous phase, in agreement with the experimental observations.

The $\mathrm{B}_{3} \mathrm{H}_{7}$ unit exhibits two types of geometries in borane compounds. One is a $\pi$-borallyl anion ligand $\left[\mathrm{B}_{3} \mathrm{H}_{7}\right]^{2-}$ with a V-shaped geometry, an analogue of a $\pi$-allyl moiety $\mathrm{C}_{3} \mathrm{H}_{9}{ }^{2-}$, which is often coordinated to a metal to form a coordination compound. ${ }^{20,21}$ Another geometry is a Lewis acid neutral ligand in a triangular shape when it is coordinated to a Lewis base to form Lewis acid-base complexes. ${ }^{22,23} \mathrm{The} \mathrm{B}_{3} \mathrm{H}_{7}$ unit in both Str640 and Str- 400 appeared to be triangular in shape but its formal oxidation state should be -2 to be consistent with the typical oxidation state of the $\mathrm{Al}^{3+}$ cation and $\mathrm{BH}_{4}^{-}$anion in the $\mathrm{AlB}_{4} \mathrm{H}_{11}$
$\left(\mathrm{Al}\left(\mathrm{BH}_{4}\right)\left(\mathrm{B}_{3} \mathrm{H}_{7}\right)\right)$ formula. The $\left[\mathrm{B}_{3} \mathrm{H}_{7}\right]^{2-}$ unit in Str-640 contains two bridging $\mathrm{H}$ atoms while that in Str- 400 contains only one bridging $\mathrm{H}$ atom (Fig. 3), which can be viewed as removing one bridging $\mathrm{H}$ atom from the $\left[\mathrm{B}_{3} \mathrm{H}_{8}\right]^{-}$unit. ${ }^{24}$ The triangular $\left[\mathrm{B}_{3} \mathrm{H}_{7}\right]$ geometry in Str-400 is the same as that in the $\mathrm{NH}_{3} \mathrm{~B}_{3} \mathrm{H}_{7}$ compound. ${ }^{23 a}$ The total energy of Str-400 is $\sim 240 \mathrm{meV}$ per fu lower than that of the Str-640 structure, indicating that the $\left[\mathrm{B}_{3} \mathrm{H}_{7}\right]^{2-}$ geometry in Str-400 is more favorable than that in Str-640.

\subsection{Chemical composition information obtained from the reaction of $\mathrm{AlB}_{4} \mathrm{H}_{11}$ with liquid ammonia}

Having obtained initial predictions of structure from theory, we turn to experimental measurement to further refine the structural information. Since the polymeric $\mathrm{AlB}_{4} \mathrm{H}_{11}$ compound did not dissolve in any organic solvent we tested and it completely decomposed in water, no spectroscopic information could be obtained from solution-based measurements. However, we found that when liquid ammonia was condensed onto the solid powder of $\mathrm{AlB}_{4} \mathrm{H}_{11}$, a clear solution emerged without any obvious bubble formation (no gaseous species). The ${ }^{11} \mathrm{~B}$ NMR spectrum of $\mathrm{AlB}_{4} \mathrm{H}_{11}$ in liquid ammonia showed two sets of boron signals that are identified as $\left[\mathrm{BH}_{4}\right]^{-}$and $\left[\mathrm{B}_{3} \mathrm{H}_{8}\right]^{-}$based on their chemical shifts and coupling with hydrogen (Fig. 4a). ${ }^{24 b, 25}$ The observation of these species is consistent with the predicted structures and with the known reactions of aluminum borohydrides and aluminum hydrides with ammonia. The absence of hydrogen as a product and the absence of borane ammonia adducts are significant observations. The products indicate $\mathrm{AlB}_{4} \mathrm{H}_{11}$ reacted with liquid ammonia rather than simply dissolving in it. The aluminum borohydride $\mathrm{Al}\left(\mathrm{BH}_{4}\right)_{3}$ reacts with stoichiometric $\mathrm{NH}_{3}$ to form $\mathrm{Al}\left(\mathrm{BH}_{4}\right)_{3}\left(\mathrm{NH}_{3}\right)_{2}$ but with excess ammonia forms $\left[\mathrm{Al}\left(\mathrm{NH}_{3}\right)_{6}\right]\left(\mathrm{BH}_{4}\right)_{3}$ which is soluble in liquid ammonia. ${ }^{26}$ The hexaminealuminum and borohydride ions are both chemically stable in liquid ammonia. In contrast, $\mathrm{AlH}_{3}$ reacts with liquid ammonia to evolve hydrogen (reaction eqn (1)). ${ }^{27}$ The amido species, $\mathrm{Al}\left(\mathrm{NH}_{2}\right)_{3}$, rearranges to form imido and nitride species, $\mathrm{Al}(\mathrm{NH})\left(\mathrm{NH}_{3}\right)$ and $\mathrm{AlN} .{ }^{27}$

$$
\mathrm{AlH}_{3}+3 \mathrm{NH}_{3} \rightarrow \mathrm{Al}\left(\mathrm{NH}_{2}\right)_{3}+3 \mathrm{H}_{2}
$$

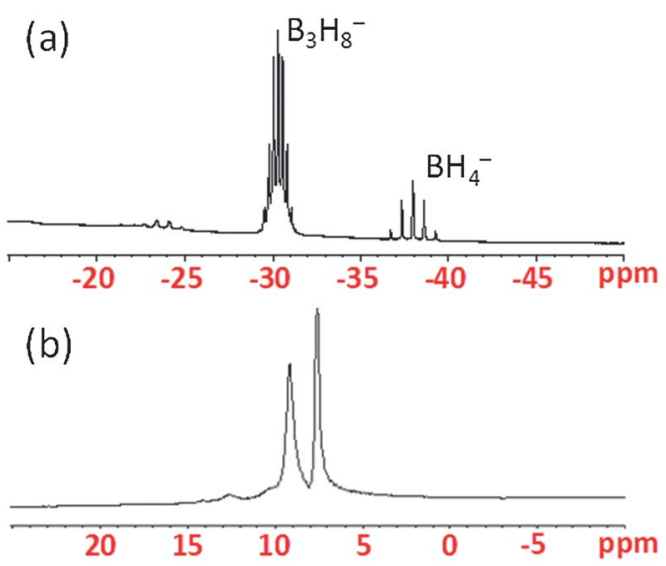

Fig. 4 (a) ${ }^{11} \mathrm{~B}$ and (b) ${ }^{27} \mathrm{Al} \mathrm{NMR}$ spectra of $\mathrm{AlB}_{4} \mathrm{H}_{11}$ in liquid ammonia. 
The absence of molecular hydrogen suggests $\mathrm{AlB}_{4} \mathrm{H}_{11}$ does not contain a terminal $\mathrm{Al}-\mathrm{H}$ bond, and the $\left[\mathrm{B}_{3} \mathrm{H}_{8}\right]^{-}$ion could arise from $\mathrm{H}^{+}$donation from $\mathrm{NH}_{3}$ coordinated to $\mathrm{Al}(\mathrm{III})$ to coordinated $\mathrm{B}_{3} \mathrm{H}_{7}{ }^{2-}$ (reaction eqn (2)).

$$
\mathrm{AlB}_{4} \mathrm{H}_{11}+6 \mathrm{NH}_{3} \rightarrow\left[\mathrm{Al}\left(\mathrm{NH}_{3}\right)_{5}\left(\mathrm{NH}_{2}\right)\right]^{2+}+\mathrm{BH}_{4}^{-}+\mathrm{B}_{3} \mathrm{H}_{8}^{-}
$$

The ${ }^{27}$ Al NMR spectrum also showed two signals $\delta 9.2$ and 7.6 $\mathrm{ppm}$, indicating that two kinds of $\mathrm{Al}$ environments, a six-coordinated aluminum and other various coordinated environments, ${ }^{26 a, 28}$ were present after $\mathrm{AlB}_{4} \mathrm{H}_{11}$ reacted with liquid ammonia (Fig. 4b). One explanation is that the amide complexes of aluminum in liquid ammonia begin to oligomerize and separate signals arise from monomer and dimer (amide bridged). An alternative explanation is that there are different types of Alcoordinated environments in $\mathrm{AlB}_{4} \mathrm{H}_{11}$, which when reacted with liquid ammonia produced two types of $\mathrm{Al}$ species. Although the analysis of ${ }^{27} \mathrm{Al}$ MAS NMR spectra primarily indicated that $\mathrm{Al}$ was considered as a single site in $\mathrm{AlB}_{4} \mathrm{H}_{11},{ }^{2}$ the existence of $\mathrm{Al}$ with multiple chemical environments in this amorphous compound is possible considering the very broad $\mathrm{Al}$ signal in the solid ${ }^{27} \mathrm{Al} \mathrm{NMR}$ spectra of $\mathrm{AlB}_{4} \mathrm{H}_{11}$ in contrast to the sharp $\mathrm{Al}$ signals in the solid of ${ }^{27} \mathrm{Al}$ NMR spectra of other amorphous compounds such as aluminate gels, glasses, or other non-crystalline components in mineral or ceramic systems. ${ }^{28}$

\subsection{Prediction of $\mathrm{AlB}_{4} \mathrm{H}_{11}$ structures using $\left[\mathrm{BH}_{4}\right]^{-}$and $\left[\mathrm{B}_{3} \mathrm{H}_{7}\right]^{2-}$ units}

Based on the structural information obtained from the NMR experiments, we subsequently further refined the theoretically predicted structures. Structures such as Str-400 and Str-640 predicted from PEGS + DFT using one formula unit have only one type of $\mathrm{Al}$ chemical environment because there is only a single $\mathrm{Al}$ in the formula unit (fu). When the PEGS + DFT calculations were extended to larger cells with two formula units (now using the experimentally confirmed $\left[\mathrm{BH}_{4}\right]^{-}$and $\left[\mathrm{B}_{3} \mathrm{H}_{7}\right]^{2-}$ anionic units), the predicted 2-fu structures of $\mathrm{AlB}_{4} \mathrm{H}_{11}$ indeed exhibited two distinct $\mathrm{Al}$ environments (the neighboring $\left[\mathrm{BH}_{4}\right]^{-}$and $\left[\mathrm{B}_{3} \mathrm{H}_{7}\right]^{2-}$ units had different orientations). Furthermore, these 2-fu structures have much lower energy than that of the 1-fu structures. Fig. 3 shows four predicted low-energy $\mathrm{AlB}_{4} \mathrm{H}_{11}$ structures: Str-0, Str-86, Str-108 and Str-260, each of which contains 2-fu. Among them, Str-0 is the lowest-energy structure, which is 86,108 , and 260,400 , and $640 \mathrm{meV}$ per fu lower than Str-86, Str-108, Str-260, and the previously predicted 1-fu Str-400 and Str-640, respectively. The low-energy 2-fu $\mathrm{AlB}_{4} \mathrm{H}_{11}$ structures (Str-0, Str-86, Str-108 and Str-260 in Fig. 3) still maintain the same $-\left[\mathrm{B}_{3} \mathrm{H}_{7}\right]-\mathrm{Al}\left(\mathrm{BH}_{4}\right)$ - polymer chain as in both Str-640 and Str-400, but the two $\mathrm{BH}_{4}$ units are now twisted relative to each other perpendicular to the chain direction, thus requiring a longer repeating unit: $-\left[\mathrm{B}_{3} \mathrm{H}_{7}\right]-\mathrm{Al}\left(\mathrm{BH}_{4}\right)-\left[\mathrm{B}_{3} \mathrm{H}_{7}\right]-$ $\mathrm{Al}\left(\mathrm{BH}_{4}\right)-$.

\subsection{Comparison of pDOS with experimental spectra}

In order to assess the correctness of predicted structures, we compare the calculated phonon density of states (pDOS) of the predicted structures of Str-0, Str-86, Str-108, Str-260 and Str-400 from PEGS + DFT with the experimental spectra, NVS from 250

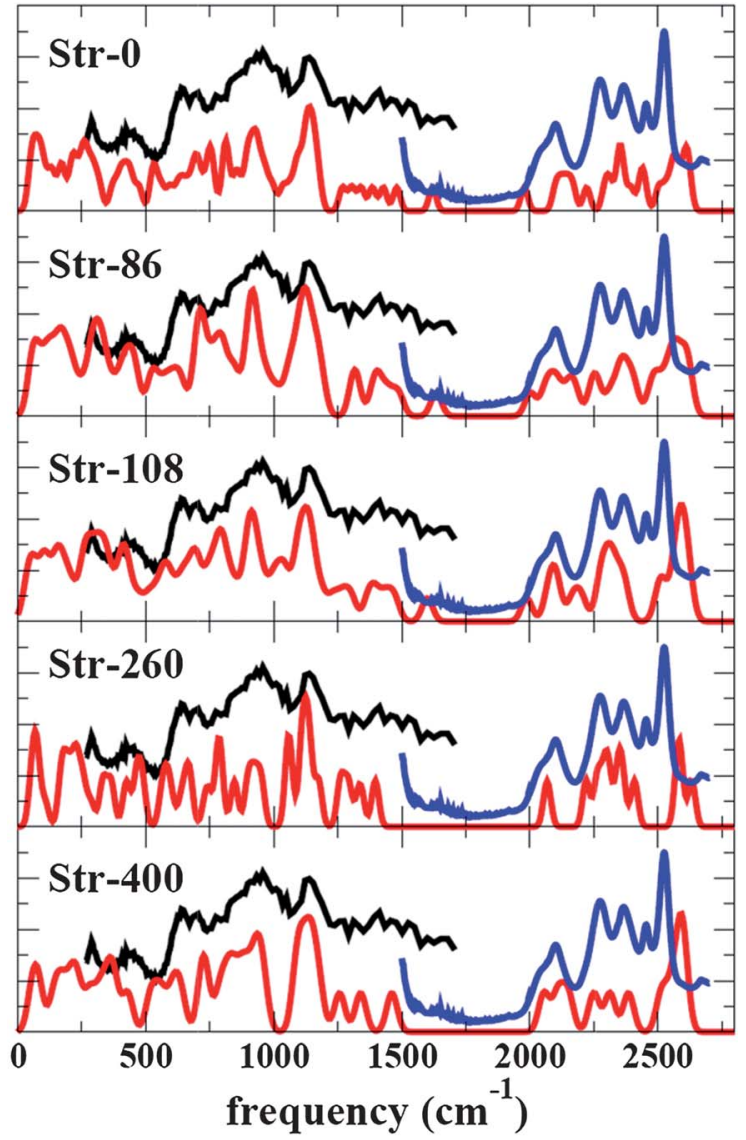

Fig. 5 Comparison of theoretical phonon density of states (red lines) of Str-0, Str-86, Str-108, Str-260, and Str-400 (Fig. 3) with the experimental neutron (black lines) and IR (blue lines) vibrational spectra.

to $1750 \mathrm{~cm}^{-1}$ and IR spectra from 1500 to $2750 \mathrm{~cm}^{-1}$ (Fig. 5). For the calculated pDOS of Str-400, there is a discrepancy below $750 \mathrm{~cm}^{-1}$ in the NVS where the peak positions of the computed pDOS are $\sim 100 \mathrm{~cm}^{-1}$ lower than experimental measurements. The peak positions in this region are dominated by the vibration of the heavy atom $(\mathrm{Al})$. Hence, we find that the pDOS of the predicted 2-fu low-energy $\mathrm{AlB}_{4} \mathrm{H}_{11}$ structures (especially Str-0, Str-86, Str-108 in Fig. 3) with two Al environments is in better agreement with the experimental results in the low-frequency region $\left(<500 \mathrm{~cm}^{-1}\right)$ than $\mathrm{Str}-400$ that contains only one $\mathrm{Al}$ environment (Fig. 5).

All predicted structures possess vibrational modes associated with B-H bonds in the region between 2000 and $2750 \mathrm{~cm}^{-1}$, which is in general agreement with the experimental IR spectra. The comparison of the pDOS of the 2-fu Str-0, Str-86 and Str108 with 2-fu Str-260 and 1-fu Str-400 shows a difference in the region of 1500 to $1750 \mathrm{~cm}^{-1}$ : the pDOS of Str-260 and Str-400 do not have a peak at $\sim 1610 \mathrm{~cm}^{-1}$ that is present in the pDOS of other 2-fu $\mathrm{AlB}_{4} \mathrm{H}_{11}$ structures. Str-0, Str-86 and Str-108 contain two $\left[\mathrm{B}_{3} \mathrm{H}_{7}\right]^{2-}$ units and the $\mathrm{B}-\mathrm{H}$ bond lengths involving bridging $\mathrm{H}$ are 1.29 and $1.44 \AA$ in one unit and 1.32 and $1.34 \AA$ in the other. These $\mathrm{B}-\mathrm{H}$ bond lengths agree well with those in the $\left[\mathrm{B}_{3} \mathrm{H}_{7}\right]$ cluster of an experimentally determined $\mathrm{NH}_{3} \mathrm{~B}_{3} \mathrm{H}_{7}$ compound: ${ }^{23 a}$ the bond lengths of the bridging $\mathrm{H}$ with nearby $\mathrm{B}$ are 1.324 and $1.324 \AA$ in a monomer and are changed to 1.294 and $1.362 \AA$ in a dimer. The eigenvectors/eigenvalues obtained via 
direct diagonalization of the dynamical matrix of the $\mathrm{AlB}_{4} \mathrm{H}_{11}$ structures (Str-0, Str-86 and Str-108) show that the bridging $\mathrm{H}$ vibrations in the first $\left[\mathrm{B}_{3} \mathrm{H}_{7}\right]$ unit contribute to modes with frequencies of $\sim 1267$ and $\sim 2143 \mathrm{~cm}^{-1}$ while the other unit vibrates at a frequency in the region from 1500 to $1750 \mathrm{~cm}^{-1}$ $\left(\sim 1618 \mathrm{~cm}^{-1}\right)$ which is in good agreement with the $\mathrm{NH}_{3} \mathrm{~B}_{3} \mathrm{H}_{7} \mathrm{IR}$ measurement $\left(1599 \mathrm{~cm}^{-1}\right) .{ }^{23 a}$ Note that the 2-fu Str-260 (ref. 29) has two $\left[\mathrm{B}_{3} \mathrm{H}_{7}\right]^{2-}$ units, but the B-H bond lengths involving bridging $\mathrm{H}$ in the two units are the same: 1.29 and $1.44 \AA$; thus, it produces no peak in the region from 1500 to $1750 \mathrm{~cm}^{-1}$ that is associated with the 1.32 and $1.34 \AA$ values in Str- 0 , Str- 86 , and Str-108).

Some $\mathrm{H}$ atoms from the $\left[\mathrm{BH}_{4}\right]$ and $\left[\mathrm{B}_{3} \mathrm{H}_{7}\right]$ units are located very close to the $\mathrm{Al}$ atoms or bridged with $\mathrm{B}$ and $\mathrm{Al}$. Although they lead to the Al-H (bridging) stretching that is characteristic of Al-H vibrational frequencies around $1500 \mathrm{~cm}^{-1}$ as observed in $\mathrm{Al}\left(\mathrm{BH}_{4}\right)_{3},{ }^{30}$ they do not lead to the formation of $\left[\mathrm{AlH}_{4}\right]$ units. If $\mathrm{AlB}_{4} \mathrm{H}_{11}$ contained an $\left[\mathrm{AlH}_{4}\right]$ cluster, which has short $\mathrm{Al}-\mathrm{H}$ bond lengths, the stretching of the Al-H bond would exhibit frequencies at $\sim 1780 \mathrm{~cm}^{-1}$. ${ }^{31}$ The absence of a peak at $\sim 1780$ $\mathrm{cm}^{-1}$ in both experimental measurements and theoretical pDOS calculations further corroborates our previous conclusion that there is no terminal $\mathrm{Al}-\mathrm{H}$ in $\mathrm{AlB}_{4} \mathrm{H}_{11}$, which is consistent with the observation of no hydrogen release when $\mathrm{AlB}_{4} \mathrm{H}_{11}$ reacted with liquid ammonia.

Although overall good agreement is observed between the pDOS of the theoretically predicted low-energy $\mathrm{AlB}_{4} \mathrm{H}_{11}$ structures (Str-0, Str- 86 and Str-108) and the experimental vibrational measurements (NVS and IR), some small discrepancies in peak positions and intensities exist (Fig. 5), which may be related to several factors. The experimental IR and NVS spectra were obtained from the amorphous $\mathrm{AlB}_{4} \mathrm{H}_{11}$ phase, while the theoretical pDOS were calculated using crystalline $\mathrm{AlB}_{4} \mathrm{H}_{11}$ structures. ${ }^{32}$ The $-\left[\mathrm{B}_{3} \mathrm{H}_{7}\right]-\mathrm{Al}\left(\mathrm{BH}_{4}\right)$ - polymer chain in the amorphous $\mathrm{AlB}_{4} \mathrm{H}_{11}$ may be twisted or reoriented like the different orientations in Str-0, Str-86, and Str-108, thus shifting the frequencies. It is also important to note that the degree of agreement between experimental NVS and simulated spectra is compound-dependent and is based on the ability to accurately model the various types of bonding interactions that are present. As such, agreement for any given compound, even if the crystal structure is known, can be less than perfect, especially in the low-frequency region, where significant shifts have been reported. ${ }^{33}$ Nonetheless, the overall good agreement between theoretical and experimental vibrational modes in the present case suggests that DFT describes the bonding interactions fairly well, and is consistent with an $\mathrm{AlB}_{4} \mathrm{H}_{11}$ amorphous phase containing distinct $\left[\mathrm{BH}_{4}\right]^{-}$ and $\left[\mathrm{B}_{3} \mathrm{H}_{7}\right]^{2-}$ units within a $-\left[\mathrm{B}_{3} \mathrm{H}_{7}\right]-\mathrm{Al}\left(\mathrm{BH}_{4}\right)-$ polymer chain structure.

\subsection{Comparison between simulated and experimental ${ }^{11} B$ NMR spectra}

To further evaluate the predicted structures, the ${ }^{11} \mathrm{~B}$ NMR chemical shifts were simulated using the GIPAW method as implemented in the Quantum ESPRESSO package. ${ }^{19}$ In the simulated ${ }^{11} \mathrm{~B}$ NMR, two sets of signals are separately located at higher and lower fields, which is consistent with the solid ${ }^{11} \mathrm{~B}$ NMR spectrum of $\mathrm{AlB}_{4} \mathrm{H}_{11}$ (Table $\mathrm{S} 2 \dagger$ ). The simulated chemical

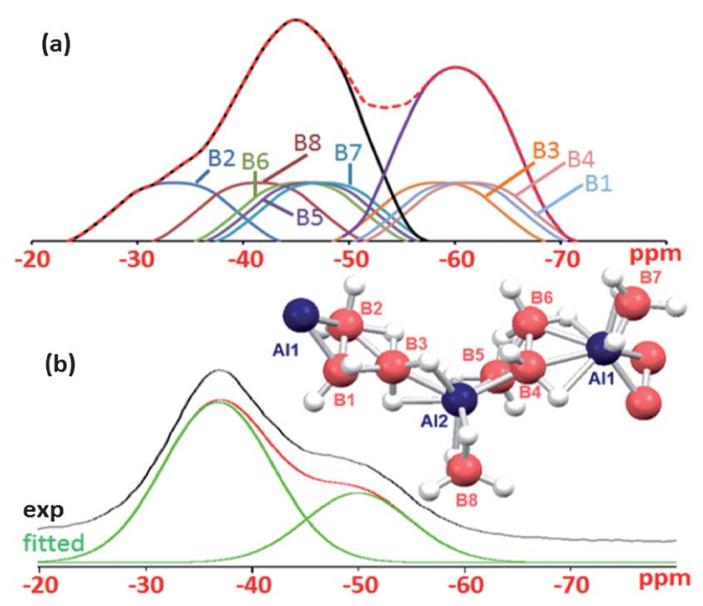

Fig. $6{ }^{11} \mathrm{~B}$ NMR spectra of $\mathrm{AlB}_{4} \mathrm{H}_{11}$ : (a) simulated based on the predicted $\operatorname{Str}-0$ and (b) experiment. ${ }^{2}$

shifts vary from structure to structure but are generally comparable with the experimental $\mathrm{AlB}_{4} \mathrm{H}_{11}$ solid-state spectrum that has two broad signals located at around $\delta-38.8$ and $-51.0 \mathrm{ppm}$ at a roughly $2: 1$ respective ratio. ${ }^{2}$ Three boron signals for the lowest-energy structure (Str-0) are located at higher field $(\delta-58.48,-60.96$, and $-61.82 \mathrm{ppm})$ and five boron signals at lower field $(\delta-33.45,-41.29,-46.50,-46.61$, and $-47.61 \mathrm{ppm})$. The ratio of the two sets of signals $(5: 3)$ is close to the experimental value $(2: 1)$. Two broad peaks created by stacking together the two sets of simulated NMR signals closely resemble the experimental solid-state ${ }^{11} \mathrm{~B}$ NMR spectrum of $\mathrm{AlB}_{4} \mathrm{H}_{11}$ with the peaks positions only differing by about $8 \sim 10 \mathrm{ppm}$ (higher field) (Fig. 6).

Two sets of boron signals are predicted for Str-86 with one set (two signals) located at $\delta-59.41$ and $-70.40 \mathrm{ppm}$ and the other set (six boron signals) at $\delta-30.5$ to $-44.13 \mathrm{ppm}$. The intensity ratio of the two sets is $3: 1$. Both Str-108 and Str-260 have four boron signals at higher field and four boron signals at lower field with the integrated peak intensity ratio of $1: 1$ (see ESI $\uparrow$ for details). A comparison of the simulated ${ }^{11} \mathrm{~B}$ NMR spectra of these structures with the solid-state ${ }^{11} \mathrm{~B}$ NMR spectrum of $\mathrm{AlB}_{4} \mathrm{H}_{11}$ indicates that the lowest-energy structure (Str-0) has the best merit in terms of both peak shapes and the peak intensity ratio. Thus we believe Str- 0 is the best representation of the $\mathrm{AlB}_{4} \mathrm{H}_{11}$ structure.

Both simulated and experimental spectra show the chemical shifts of all boron atoms at a range from $\delta-30$ to $-70 \mathrm{ppm}$, which supports the triangle-shaped $\mathrm{B}_{3}$ unit rather than a Vshaped $\pi$-borallyl anion ligand $\left[\mathrm{B}_{3} \mathrm{H}_{7}\right]^{2-}$ in which the two terminal boron signals would appear at about $\delta+8 \mathrm{ppm}$ and the central boron at about $\delta+20 \mathrm{ppm} .{ }^{21}$ The ${ }^{11} \mathrm{~B}$ chemical shift of the Lewis acid $\mathrm{B}_{3} \mathrm{H}_{7}$ is very dependent on the coordinated Lewis base, and the observed ${ }^{11} \mathrm{~B}$ NMR shift, ranging from at least $\delta+8$ to $-53 \mathrm{ppm},{ }^{23}$ is consistent with the triangular boron unit.

\subsection{Formation mechanism of $\mathrm{AlB}_{4} \mathrm{H}_{11}$}

Based on the identified structure of $\mathrm{AlB}_{4} \mathrm{H}_{11}$, we performed a preliminary study of its formation mechanism. The reaction of $\mathrm{Al}\left(\mathrm{BH}_{4}\right)_{3}$ and diborane was monitored by ${ }^{11} \mathrm{~B}$ and ${ }^{11} \mathrm{~B}\left\{{ }^{1} \mathrm{H}\right\}$ 

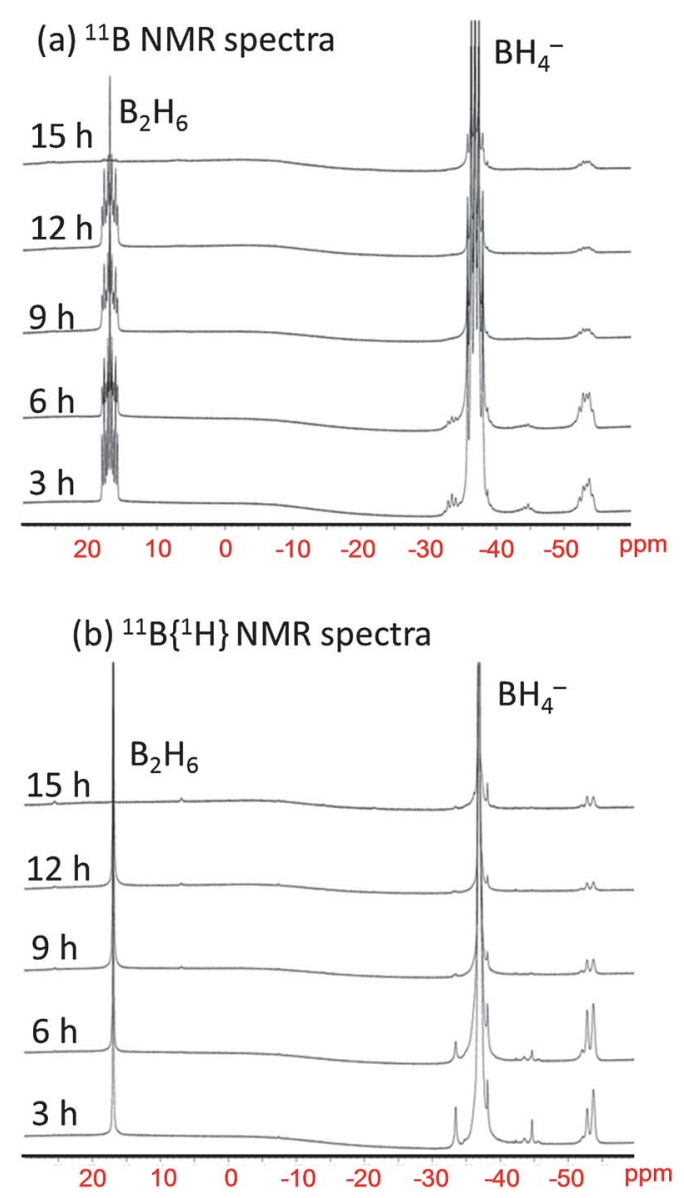

Fig. 7 (a) ${ }^{11} \mathrm{~B}$ and (b) ${ }^{11} \mathrm{~B}\left\{{ }^{1} \mathrm{H}\right\}$ NMR spectra of the reaction of $\mathrm{Al}\left(\mathrm{BH}_{4}\right)_{3}$ with $\mathrm{B}_{2} \mathrm{H}_{6}$ in benzene at $100{ }^{\circ} \mathrm{C}$. Samples were extracted at three-hour intervals.

NMR. Each of the starting materials alone, $\mathrm{Al}\left(\mathrm{BH}_{4}\right)_{3}$ or $\mathrm{B}_{2} \mathrm{H}_{6}$, are found to be stable at $100{ }^{\circ} \mathrm{C}$ in benzene solution. The ${ }^{11} \mathrm{~B}$ and ${ }^{11} \mathrm{~B}\left\{{ }^{1} \mathrm{H}\right\}$ NMR spectra of the mixture of $\mathrm{Al}\left(\mathrm{BH}_{4}\right)_{3}$ and $\mathrm{B}_{2} \mathrm{H}_{6}$ show that when the reaction started, two sets of small peaks simultaneously appeared at $\delta-33.4,-36.89,-38.1,-43.6$, and $-44.7 \mathrm{ppm}$ and at $\delta-52.6$ and $53.8 \mathrm{ppm}$ (Fig. 7). These peak positions are close to, but not identical to, the two broad peaks observed in the solid ${ }^{11} \mathrm{~B}$ NMR spectra of $\mathrm{AlB}_{4} \mathrm{H}_{11}{ }^{2}$ The lowfield peaks at around $\delta-33.4$ to $-44.7 \mathrm{ppm}$ are likely related to an intermediate $\left[\mathrm{HAl}\left(\mathrm{BH}_{4}\right)_{2}\right]_{n}$ with different states $(n)$ of aggregation, ${ }^{34}$ and the high-field peaks at $\delta-52.6$ and $-53.8 \mathrm{ppm}$ might be related to a boron hydride species such as $\mathrm{B}_{3} \mathrm{H}_{7}$ that does not exist alone but interacts with $\left[\mathrm{HAl}\left(\mathrm{BH}_{4}\right)_{2}\right]_{n}$ or $\left.\mathrm{AlIBH}_{4}\right)_{3}$. Nöth showed that diborane dissociates in THF solution to form $\mathrm{THF} \cdot \mathrm{BH}_{3}$, and the equilibrium among $\mathrm{Al}\left(\mathrm{BH}_{4}\right)_{3}, \mathrm{HAl}\left(\mathrm{BH}_{4}\right)_{2}$ and $\mathrm{THF} \cdot \mathrm{BH}_{3}$ is dynamic. ${ }^{34 b}$ Maybury and Larrabee measured the kinetics of deuterium and boron exchange between $\mathrm{Al}\left(\mathrm{BH}_{4}\right)_{3}$ and $\mathrm{B}_{2} \mathrm{D}_{6}$ (and ${ }^{10} \mathrm{~B}_{2} \mathrm{D}_{6}$ ) in the gas phase, ${ }^{35}$ and proposed a mechanism involving thermal dissociation of both $\mathrm{Al}\left(\mathrm{BH}_{4}\right)_{3}$ and $\mathrm{B}_{2} \mathrm{D}_{6}$ followed by a rate-limiting reaction between $\mathrm{BH}_{3}$ (formed from $\mathrm{Al}\left(\mathrm{BH}_{4}\right)_{3}$ dissociation) and $\mathrm{B}_{2} \mathrm{D}_{6}$. These experimental results led us to propose a formation mechanism of $\mathrm{AlB}_{4} \mathrm{H}_{11}$ as: (1) reaction of $\mathrm{B}_{2} \mathrm{H}_{6}$ with a $\mathrm{BH}_{3}$ unit from $\mathrm{Al}\left(\mathrm{BH}_{4}\right)_{3}$ formed [HAl $\left(\mathrm{BH}_{4}\right)_{2}$ ] and $\mathrm{B}_{3} \mathrm{H}_{7}$ with one $\mathrm{H}_{2}$ being eliminated; (2) two intermediates of $\left[\mathrm{HAl}\left(\mathrm{BH}_{4}\right)_{2}\right]$ and $\mathrm{B}_{3} \mathrm{H}_{7}$ interacted once they

$$
\begin{gathered}
\mathrm{Al}\left(\mathrm{BH}_{4}\right)_{3}+\mathrm{B}_{2} \mathrm{H}_{6} \rightarrow 1 / n\left[\left\{\mathrm{HAl}\left(\mathrm{BH}_{4}\right)_{2}\right\}_{n} \cdots \mathrm{B}_{3} \mathrm{H}_{7}\right]^{\ddagger}+\mathrm{H}_{2} \rightarrow \\
1 / n\left[\mathrm{Al}\left(\mathrm{B}_{3} \mathrm{H}_{7}\right)\left(\mathrm{BH}_{4}\right)\right]_{n}+1 / 2 \mathrm{~B}_{2} \mathrm{H}_{6}+\mathrm{H}_{2}
\end{gathered}
$$

Scheme 1 The formation mechanism of $\mathrm{AlB}_{4} \mathrm{H}_{11}$.

formed; and (3) a $-\left[\mathrm{B}_{3} \mathrm{H}_{7}\right]-\mathrm{Al}\left(\mathrm{BH}_{4}\right)-$ polymer chain was formed as shown in Scheme 1.

The mechanism is supported by the observation that $\mathrm{Al}\left(\mathrm{BH}_{4}\right)_{3}$ reacts with $\mathrm{CO}$ at ambient temperature to form $\left[\mathrm{HAl}\left(\mathrm{BH}_{4}\right)_{2}\right]_{n}$ : the $\mathrm{CO}$ molecule pulls a $\mathrm{BH}_{3}$ moiety from $\mathrm{Al}\left(\mathrm{BH}_{4}\right)_{3}$ to produce $\mathrm{CO} \cdot \mathrm{BH}_{3} \cdot{ }^{34 a} \mathrm{It}$ is reasonable to assume that $\mathrm{B}_{2} \mathrm{H}_{6}$ performs the same function as $\mathrm{CO}$ to react with a $\mathrm{BH}_{3}$ group of $\mathrm{Al}\left(\mathrm{BH}_{4}\right)_{3}$ to form a $\mathrm{B}_{3} \mathrm{H}_{9}$ unit and $\left[\mathrm{HAl}\left(\mathrm{BH}_{4}\right)_{2}\right]$. For the room-temperature reaction of $\mathrm{Al}\left(\mathrm{BH}_{4}\right)_{3}$ with $\mathrm{CO}$, two signals of $\mathrm{BH}_{4}{ }^{-}$were detected at $\delta-38.0$ and $-43.3 \mathrm{ppm}$ probably due to the formation of two states of aggregation of $\left[\mathrm{HAl}\left(\mathrm{BH}_{4}\right)_{2}\right]_{n}(n=1$ and 2$)$. This explanation is supported by the formation of both monomer and dimer compounds, $\left[\mathrm{HGa}\left(\mathrm{BH}_{4}\right)_{2}\right]$ and $\left[\mathrm{HGa}\left(\mathrm{BH}_{4}\right)_{2}\right]_{2}$, in a similar reaction of $\mathrm{Ga}\left(\mathrm{BH}_{4}\right)_{3}$ with $\mathrm{CO} .{ }^{36}$ Thus, at an elevated temperature, reaction of $\mathrm{Al}\left(\mathrm{BH}_{4}\right)_{3}$ with $\mathrm{B}_{2} \mathrm{H}_{6}$ might have led to higher oligomers of $\left[\mathrm{HAl}\left(\mathrm{BH}_{4}\right)_{2}\right]_{n}$, and the small peaks observed at $\delta-33.4$ to $-44.7 \mathrm{ppm}$ are likely representing polymeric $\left[\mathrm{HAl}\left(\mathrm{BH}_{4}\right)_{2}\right]_{n}$ with more than two different states of oligomers. The initially formed polymer species probably had limited solubility in the reaction solution, so these peaks in their ${ }^{11} \mathrm{~B}$ NMR spectra gradually diminished as the reaction proceeded (Fig. 7).

While one set of signals at lower field from $\delta-33.4$ to -44.7 $\mathrm{ppm}$ is reasonably assigned to the intermediate of $\mathrm{HAl}\left(\mathrm{BH}_{4}\right)_{2}$, another set of signals at high field from $\delta-52.6$ and $-53.8 \mathrm{ppm}$ is considered to be related to one of the boron atoms in the $\mathrm{B}_{3} \mathrm{H}_{7}$ unit which is produced from the reaction of $\mathrm{B}_{2} \mathrm{H}_{6}$ with a $\mathrm{BH}_{3}$ followed by eliminating an $\mathrm{H}_{2}$ molecule. This reaction has been investigated extensively both theoretically and experimentally. ${ }^{38}$ The boron signals appearing at such a high field region of ${ }^{11} \mathrm{~B}$ NMR spectra is unusual - only when boron atoms are located at unique environments, especially in an open-skeleton structure. ${ }^{37}$ One boron signal in several Lewis-acid-base adducts of triborane, $\mathrm{L} \cdot \mathrm{B}_{3} \mathrm{H}_{7}$, appeared at this high field region. ${ }^{23}$ The three $\mathrm{B}$ atoms in $\mathrm{B}_{3} \mathrm{H}_{7}$ display two NMR signals over a wide range. The chemical shifts depend heavily on the properties of the coordinated Lewis base. The coordinated $\mathrm{B}$ is distinguishable from the other two in the adduct, $\mathrm{L} \cdot \mathrm{B}_{3} \mathrm{H}_{7}{ }^{23} \mathrm{In} \mathrm{THF} \cdot \mathrm{B}_{3} \mathrm{H}_{7}$, the coordinated boron signal was located at $\delta+12.8$ and the other two $\mathrm{B}$ at +8.4 ppm. ${ }^{23 e}$ In contrast, the coordinated boron signal in the Lewis adduct $\mathrm{PH}_{3} \cdot \mathrm{B}_{3} \mathrm{H}_{7}$ appeared at $\delta-51.3 \mathrm{ppm}$, which is close to the small ${ }^{11} \mathrm{~B}$ NMR peaks observed in the current experiment, and the other two $\mathrm{B}$ signals appeared at $\delta-10.2 \mathrm{ppm}^{23 d}$ The exact state of $\mathrm{B}_{3} \mathrm{H}_{7}$ in the reaction system is unknown and seems to be interacting with $\left[\mathrm{HAl}\left(\mathrm{BH}_{4}\right)_{2}\right]_{n}$ as indicated in the predicted structures where each $\mathrm{B}_{3} \mathrm{H}_{7}$ unit is connected to an $\mathrm{Al}$ atom through a bridge hydrogen. Thus, we assumed the small peaks at $\delta-52.6$ and $-51.3 \mathrm{ppm}$ were associated with a $\mathrm{B}_{3} \mathrm{H}_{7}$ group that was interacting with $\left[\mathrm{HAl}\left(\mathrm{BH}_{4}\right)_{2}\right]_{n}$ in some way. At an initial stage, these species had some solubility in the solution so they could be detected in ${ }^{11} \mathrm{~B}$ NMR spectra. This explanation is consistent with the simulated ${ }^{11} \mathrm{~B}$ NMR spectra in which the chemical shifts of $\mathrm{B}$ in the $\mathrm{B}_{3} \mathrm{H}_{7}$ group in Str- 0 are distributed over a wide range from $\delta-33.45$ to $-61.82 \mathrm{ppm}$. 


$$
\begin{gathered}
\mathrm{Al}\left(\mathrm{BH}_{4}\right)_{3} \leftrightarrow \mathrm{HAl}\left(\mathrm{BH}_{4}\right)_{2}+\mathrm{BH}_{3} \\
\mathrm{BH}_{3}+\mathrm{B}_{2} \mathrm{H}_{6} \rightarrow \mathrm{B}_{3} \mathrm{H}_{9} \\
\mathrm{~B}_{3} \mathrm{H}_{9}+\mathrm{HAl}\left(\mathrm{BH}_{4}\right)_{2} \rightarrow \mathrm{Al}\left(\mathrm{B}_{3} \mathrm{H}_{8}\right)\left(\mathrm{BH}_{4}\right)_{2}+\mathrm{H}_{2} \\
\mathrm{Al}\left(\mathrm{B}_{3} \mathrm{H}_{8}\right)\left(\mathrm{BH}_{4}\right)_{2} \rightarrow 1 / n\left[\mathrm{Al}\left(\mathrm{B}_{3} \mathrm{H}_{7}\right)\left(\mathrm{BH}_{4}\right)\right]_{n}+\mathrm{BH}_{3}+\mathrm{H}_{2} \\
\mathrm{BH}_{3} \rightarrow 1 / 2 \mathrm{~B}_{2} \mathrm{H}_{6}
\end{gathered}
$$

The sequence of reactions in Scheme 2 adds up to the net reaction for the formation of $\mathrm{AlB}_{4} \mathrm{H}_{11}$.

$$
\mathrm{Al}\left(\mathrm{BH}_{4}\right)_{3}+1 / 2 \mathrm{~B}_{2} \mathrm{H}_{6} \rightarrow \mathrm{AlB}_{4} \mathrm{H}_{11}+2 \mathrm{H}_{2}
$$

Scheme 2 An alternative formation mechanism for $\mathrm{AlB}_{4} \mathrm{H}_{11}$.

An alternative mechanism involved $\mathrm{B}_{2} \mathrm{H}_{6}$ reacting with $\mathrm{BH}_{3}$ from $\mathrm{Al}\left(\mathrm{BH}_{4}\right)_{3}$ dissociation to form $\mathrm{B}_{3} \mathrm{H}_{9}$. This species reacts with $\mathrm{HAl}\left(\mathrm{BH}_{4}\right)_{2}$ with the elimination of $\mathrm{H}_{2}$ to form a coordinated $\mathrm{B}_{3} \mathrm{H}_{8}{ }^{-}$anion. A second mole of $\mathrm{H}_{2}$ is eliminated as a second $\mathrm{BH}_{3}$ (from coordinated $\mathrm{BH}_{4}{ }^{-}$) evolves from the intermediate in a reaction of coordinated $\mathrm{B}_{3} \mathrm{H}_{8}{ }^{-}$with coordinated $\mathrm{BH}_{4}{ }^{-}$. The proposed reaction sequence is shown in Scheme 2.

This alternative mechanism is supported by reports reviewed by Beall et al. in which the formation of a stable $\mathrm{B}_{3} \mathrm{H}_{8}{ }^{-}$anion from a reaction of diborane with a metal borohydride was observed. ${ }^{39}$ It was suggested that $\mathrm{B}_{3} \mathrm{H}_{7}{ }^{2-}$ is a possible intermediate. Gaines et al. noted that the triborohydride ion can be prepared by reaction of metal borohydrides with diborane in ether solutions at $100{ }^{\circ} \mathrm{C} .{ }^{40}$ These authors note that the preparation of $\mathrm{B}_{3} \mathrm{H}_{8}{ }^{-}$from $\mathrm{B}_{2} \mathrm{H}_{6}$ and a metal borohydride requires a temperature of about $100{ }^{\circ} \mathrm{C}$ to proceed at a reasonable rate. The elimination of $\mathrm{H}_{2}$, either before the $\mathrm{B}_{3}$ species is formed or after, is most likely the rate-limiting step. In this alternative reaction sequence, this intermediate may account for the unusually high field resonances at $\delta-52.6$ and $-53.8 \mathrm{ppm}$ in which both a monomer and bridged dimer monohydride are initially formed.

We are confident to conclude from the overall good agreement between theoretical and experimental vibrational modes that the $\mathrm{AlB}_{4} \mathrm{H}_{11}$ amorphous phase contains distinct $\left[\mathrm{BH}_{4}\right]$ and $\left[\mathrm{B}_{3} \mathrm{H}_{7}\right]$ units and also likely two $\mathrm{Al}$ environments, and it forms a $-\left[\mathrm{B}_{3} \mathrm{H}_{7}\right]-\mathrm{Al}\left(\mathrm{BH}_{4}\right)-$ polymer chain. The lowest-energy structure (Str-0) has the best merit based not only on the computed ground-state energy, but also on the best observed agreement with NVS, IR, and NMR. The slight discrepancy found between the predicted properties of Str-0 and the experimental observations may be due to some twisting or reorientation of the $-\left[\mathrm{B}_{3} \mathrm{H}_{7}\right]-\mathrm{Al}\left(\mathrm{BH}_{4}\right)-$ polymer chain as the chain gets longer.

\section{Conclusions}

The structure of amorphous $\mathrm{AlB}_{4} \mathrm{H}_{11}$ was predicted theoretically and then assessed experimentally, and the formation mechanism of $\mathrm{AlB}_{4} \mathrm{H}_{11}$ was also proposed. The predicted structures explicitly show a $-\left[\mathrm{B}_{3} \mathrm{H}_{7}\right]-\mathrm{Al}\left(\mathrm{BH}_{4}\right)$ - polymer chain in which $\mathrm{B}_{3} \mathrm{H}_{7}$ exists in a triangular shape rather than as a $\mathrm{V}$-shaped $\pi$-borallyl anion ligand. The $\mathrm{BH}_{4}$ and $\mathrm{B}_{3} \mathrm{H}_{7}$ moieties in $\mathrm{AlB}_{4} \mathrm{H}_{11}$ were converted to $\mathrm{BH}_{4}{ }^{-}$and $\mathrm{B}_{3} \mathrm{H}_{8}{ }^{-}$in liquid ammonia, which was identified using ${ }^{11} \mathrm{~B}$ NMR spectra. Two $\mathrm{Al}$ signals were also observed in ${ }^{27} \mathrm{Al} \mathrm{NMR}$ of the $\mathrm{AlB}_{4} \mathrm{H}_{11}$ in liquid ammonia, which is consistent with the predicted lowest-energy structures (Str-0 and Str-86). The computed phonon densities of states of the predicted structures are in good agreement with the experimental vibrational measurements over a wide range of frequencies. The calculated ${ }^{11} \mathrm{~B}$ NMR chemical shifts for the predicted structures fall within the range of the experimentally measured values, especially for Str-0, whose simulated NMR peaks agree well with the experimental result. Preliminary study of the formation mechanism of $\mathrm{AlB}_{4} \mathrm{H}_{11}$ using ${ }^{11} \mathrm{~B} \mathrm{NMR}$ spectroscopy provides two possible pathways for the formation of $\mathrm{AlB}_{4} \mathrm{H}_{11}$.

\section{Acknowledgements}

This work was supported by the U.S. Department of Energy, Office of Energy Efficiency and Renewable Energy, under Contract no. DE-FC3605GO15062. Y. Z., Y. W. and C. W. gratefully acknowledge financial support from the U.S. Department of Energy under grant nos DE-FC36-08GO18136 and DE-FG02-07ER46433, and funding from Ford Motor Company under the University Research Program. T.J.U. and W.Z. gratefully acknowledge financial support from the U.S. Department of Energy under grant nos DE-EE0002978 and DEAI-01-05EE11104. ORNL is managed and operated for the DOE by UT Battelle, LLC under contract DE-AC05-00OR22725. Research at ORNL is also supported by the Office of Energy Efficiency and Renewable Energy, Office of Hydrogen, Fuel Cell, and Infrastructure Technologies of DOE in conjunction with the DOE Metal Hydride Center of Excellence. The participation of Douglas A. Knight was made possible by appointment in the ORNL Postgraduate Program administrated by the Oak Ridge Institute for Science and Education. The authors from OSU are grateful to Profs. Edward A. Meyers and Thomas Evans for their very valuable comments. Critical comments of Dr Robert C. Bowman, Jr are also greatly acknowledged.

\section{Notes and references}

1 F. L. Himpsl, Jr and A. C. Bond, J. Am. Chem. Soc., 1981, 103, 1098. 2 J.-C. Zhao, D. A. Knight, G. M. Brown, C. Kim, S.-J. Hwang, J. W. Reiter, R. C. Bowman, Jr, J. A. Zan and J. G. Kulleck, J. Phys. Chem. C, 2009, 113, 2.

3 V. Ozolinšs, E. H. Majzoub and C. Wolverton, Phys. Rev. Lett., 2008, 100, 135501.

4 Y. Zhang, E. H. Majzoub, V. Ozoliņš and C. Wolverton, Phys. Rev. B: Condens. Matter Mater. Phys., 2010, 82, 174107.

5 Y. Zhang, E. H. Majzoub, V. Ozolins and C. Wolverton, J. Phys. Chem. C, 2012, 116, 10522.

6 V. Ozolinšs, E. H. Majzoub and C. Wolverton, J. Am. Chem. Soc., 2009, 131, 230.

7 The mention of all commercial suppliers in this paper is for clarity. This does not imply our recommendation or endorsement of these suppliers.

8 T. J. Udovic, C. M. Brown, J. B. Leão, P. C. Brand, R. D. Jiggetts, R. Zeitoun, T. A. Pierce, I. Peral, J. R. D. Copley, Q. Huang, D. A. Neumann and R. J. Fields, Nucl. Instrum. Methods Phys. Res., Sect. A, 2008, 588, 406.

9 (a) H. I. Schlesinger, R. T. Sanderson and A. B. Burg, J. Am. Chem. Soc., 1940, 62, 3421; (b) H. I. Schlesinger, H. C. Brown and E. K. Hyde, J. Am. Chem. Soc., 1953, 75, 209.

10 C. Narayana and M. A. Periasamy, J. Organomet. Chem., 1987, 323, 145.

11 G. Kresse and D. Joubert, Phys. Rev. B: Condens. Matter Mater. Phys., 1999, 59, 1758.

12 J. P. Perdew and Y. Wang, Phys. Rev. B: Condens. Matter Mater. Phys., 1992, 45, 13244.

13 H. J. Monkhorst and J. D. Pack, Phys. Rev. B: Solid State, 1976, 13, 5188. 
14 (a) C. Wolverton, V. Ozolinš and M. Asta, Phys. Rev. B: Condens Matter Mater. Phys., 2004, 69, 144109; (b) C. Wolverton and V. Ozolinš, Phys. Rev. B: Condens. Matter Mater. Phys., 2007, 75, 064101; (c) C. Wolverton, D. J. Siegel, A. R. Akbarzadeh and V. Ozolins, J. Phys.: Condens. Matter, 2008, 20, 064228.

15 E. H. Majzoub and V. Ozolinšs, Phys. Rev. B: Condens. Matter Mater. Phys., 2008, 77, 104115.

16 C. Kittel, Introduction to Solid State Physics, John Wiley \& Sons, 8th edn, 2005.

17 M. W. Schmidt, K. K. Baldridge, J. A. Boatz, S. T. Elbert, M. S. Gordon, J. Jensen, S. Koseki, N. Matsunaga, K. A. Nguyen, $\mathrm{S}$. Su, T. L. Windus, M. Dupuis and J. A. Montgomery, J. Comput. Chem., 1993, 14, 1347.

18 (a) G. Kresse, J. Furthmuller and J. Hafiner, Europhys. Lett., 1995 , 32, 729; (b) T. Yildirim, Chem. Phys., 2000, 261, 205.

19 P. Giannozzi, S. Baroni, N. Bonini, M. Calandra, R. Car, C. Cavazzoni, D. Ceresoli, G. L. Chiarotti, M. Cococcioni, I. Dabo, A. Dal Corso, S. Fabris, G. Fratesi, S. de Gironcoli, R. Gebauer, U. Gerstmann, C. Gougoussis, A. Kokalj, M. Lazzeri, L. Martin-Samos, N. Marzari, F. Mauri, R. Mazzarello, S. Paolini, A. Pasquarello, L. Paulatto, C. Sbraccia, S. Scandolo, G. Sclauzero, A. P. Seitsonen, A. Smogunov, P. Umari and R. M. Wentzcovitch, J. Phys.: Condens. Matter, 2009, 21, 395502.

20 (a) A. R. Kane and E. L. Muetterties, J. Am. Chem. Soc., 1971, 93, 1041; (b) L. J. Guggenberger, A. R. Kane and E. L. Muetterties, J. Am. Chem. Soc., 1972, 94, 5665; (c) X. Lei, A. K. Bandyopadhyay, M. Shang and T. P. Fehlner, Organometallics, 1999, 18, 2294.

21 (a) C. E. Housecroft, S. M. Owen, P. R. Raithby and B. A. M. Shaykh, Organometallics, 1990, 9, 1617; (b) X. Lei, M. Shang and T. P. Fehlner, Organometallics, 1998, 17, 1558; (c) C. E. Housecroft, B. M. A. Shaykh, A. L. Rheingold and B. S. Haggery, Inorg. Chem., 1991, 30, 125

22 (a) C. E. Nordman and C. Reimann, J. Am. Chem. Soc., 1959, 81, 3538; (b) J. D. Glore, J. W. Rathke and R. Schaefer, Inorg. Chem. $1973,12,2175$

23 (a) C. W. Yoon, P. J. Carroll and L. G. Sneddon, J. Am. Chem. Soc., 2009, 131, 855; (b) H. Beall and C. H. Bushweller, Chem. Rev., 1976, 15, 741; (c) L. D. Brown and W. N. Lipscomb, Inorg. Chem., 1977, 16, 1; (d) V. L. Bishop and G. Kodama, Inorg. Chem., 1981, 20, 2724; (e) G. Kodama, Inorg. Chem., 1975, 14, 452.

24 (a) C. R. Peters and C. E. Nordman, J. Am. Chem. Soc., 1960, 82 5758; (b) Z. Huang, G. King, X. Chen, J. Hoy, T. Yisgedu, H. K. Lingam, S. G. Shore, P. M. Woodward and J.-C. Zhao, Inorg. Chem., 2010, 49, 8185 .

25 (a) D. Y. Kim, Y. Yang, J. R. Abelson and G. S. Girolami, Inorg. Chem., 2007, 46, 9060; (b) R. T. Paine, E. Fukushima and S. B. W. Roeder, Chem. Phys. Lett., 1976, 32, 566.
26 (a) Y. Guo, X. Yu, W. Sun, D. Sun and W. Yang, Angew. Chem., Int. Ed., 2011, 50, 1087; (b) N. Davies, P. H. Bird and M. G. H. Wallbridge, J. Chem. Soc. A, 1968, 2269; (c) P. H. Bird and M. G. H. Wallbridge, J. Chem. Soc. A, 1967, 664; (d) P. C. Maybury, J. C. Davis Jr and R. A. Patz, Inorg. Chem., 1969, $8,160$.

27 L. Maya, Adv. Ceram. Mater., 1986, 1, 150.

28 J. D. M. Kenneth and E. S. Mark, Pergamon Materials Series, Pergamon, Oxford, vol. 6, 2002, p. 271.

29 Although the pDOS of $\mathrm{AlB}_{4} \mathrm{H}_{11}$-Str-400 has no peaks in the region of $1500-2000 \mathrm{~cm}^{-1}$, we ignore the discussion of the structure in text because it has significantly higher energy than Str- 0 , and it does not contain theexperimentally suggested two $\mathrm{B}$ and two $\mathrm{Al}$ environments.

30 (a) A. Al-Kahtani, D. L. Williams and J. W. Nibler, J. Phys. Chem. A, 1998, 102, 537; (b) D. A. Coe and J. W. Nibler, Spectrochim. Acta, Part A, 2003, 59, 1565.

31 E. H. Majzoub, K. F. Mccarty and V. Ozolinš, Phys. Rev. B: Condens. Matter Mater. Phys., 2005, 71, 024118.

32 (a) V. Aleksa, G. A. Guirgis, A. Horn, P. Klaeboe, R. J. Liberatore and C. J. Nielsen, Vib. Spectrosc., 2012, 61, 167; (b) L. Zhang, S. Watanabe, I. Noda and Y. Wu, Appl. Spectrosc., 2011, 65, 1403.

33 N. Verdal, T. J. Udovic, J. J. Rush, V. Stavila, H. Wu, W. Zhou and T. Jenkins, J. Chem. Phys., 2011, 135, 094501.

34 (a) A. J. Downs and L. A. Jones, Polyhedron, 1994, 13, 2401; (b) H. Nöth and R. Rurlānder, Inorg. Chem., 1981, 20, 1062.

35 P. C. Maybury and J. C. Larrabee, Inorg. Chem., 1963, 2, 885.

36 A. J. Downs, L. A. Harman, P. D. Thomas and C. R. Pulham, Polyhedron, 1995, 14, 935.

37 S. Heřmānek, Chem. Rev., 1992, 92, 325.

38 (a) J. F. Stanton, W. N. Lipscomb and R. J. Bartlett, J. Am. Chem. Soc., 1989, 111, 5165; (b) R. Greatrex, N. G. Greenwood and S. M. Lucas, J. Am. Chem. Soc., 1989, 111, 8721; (c) S. A. Fridmann and T. P. Fehlner, J. Am. Chem. Soc., 1971, 93, 2824; (d) S. A. Fridmann and T. P. Fehlner, Inorg. Chem., 1972, 11, 936; (e) W. N. Lipscomb, H. F. Stanton, W. B. Connick and D. H. Magera, Pure Appl. Chem., 1991, 63, 335; $(f)$ R. E. Enrione and R. Schaeffer, J. Inorg. Nucl. Chem., 1961, 18, 103; $(g)$ L. H. Long, J. Inorg. Nucl. Chem., 1970, 32, 1097; (h) H. Fernández, J. Grotewold, C. M. Previtall and F. F. Bioquímica, J. Chem. Soc., Dalton Trans., 1973, 2090; (i) B. Brellochs and H. Binder, Angew. Chem., Int. Ed. Engl., 1988, 27, 262.

39 (a) H. Beall and D. F. Gaines, Inorg. Chim. Acta, 1999, 289, 1; (b) R. A. Godfroid, T. G. Hill, T. P. Onak and S. G. Shore, J. Am. Chem. Soc., 1994, 116, 12107.

40 D. F. Gaines, R. Schaeffer and F. Tebbe, Inorg. Chem., 1963, 2, 526. 